\title{
LA-10601-HDR
}

UC-66b

Issued: November 1985

LA--10601-HDR

DE86 005838

\section{The Transfer of Hot Dry Rock Technology}

\author{
Morton C. Smith
}

\section{DISCLAIMER}

This report was prepared as an account of work sponsored by an agency of the United States Government. Neither the United States Government nor any agency thereof, nor any of their employees, makes any warranty, express or implied, or assumes any legal liability or responsibility for the accuracy, completeness, or usefulness of any information, apparatus, product, or process disclosed, or represents that its use would not infringe privately owned rights. Reference herein to any specific commercial product, process, or service by trade name, trademark, manufacturer, or otherwise does not necessarily constitute or imply its endorsement, recommendation, or favoring by the United States Government or any agency thereof. The views and opinions of authors expressed herein do not necessarily state or reflect those of the United States Government or any agency thereof.
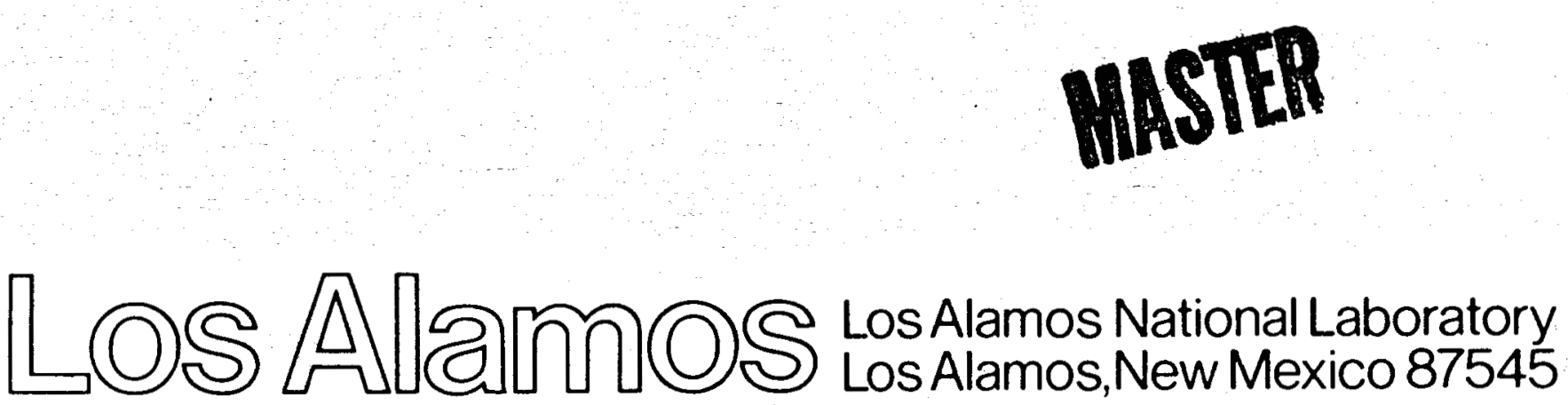


\section{DISCLAIMER}

This report was prepared as an account of work sponsored by an agency of the United States Government. Neither the United States Government nor any agency Thereof, nor any of their employees, makes any warranty, express or implied, or assumes any legal liability or responsibility for the accuracy, completeness, or usefulness of any information, apparatus, product, or process disclosed, or represents that its use would not infringe privately owned rights. Reference herein to any specific commercial product, process, or service by trade name, trademark, manufacturer, or otherwise does not necessarily constitute or imply its endorsement, recommendation, or favoring by the United States Government or any agency thereof. The views and opinions of authors expressed herein do not necessarily state or reflect those of the United States Government or any agency thereof. 


\section{DISCLAIMER}

Portions of this document may be illegible in electronic image products. Images are produced from the best available original document. 


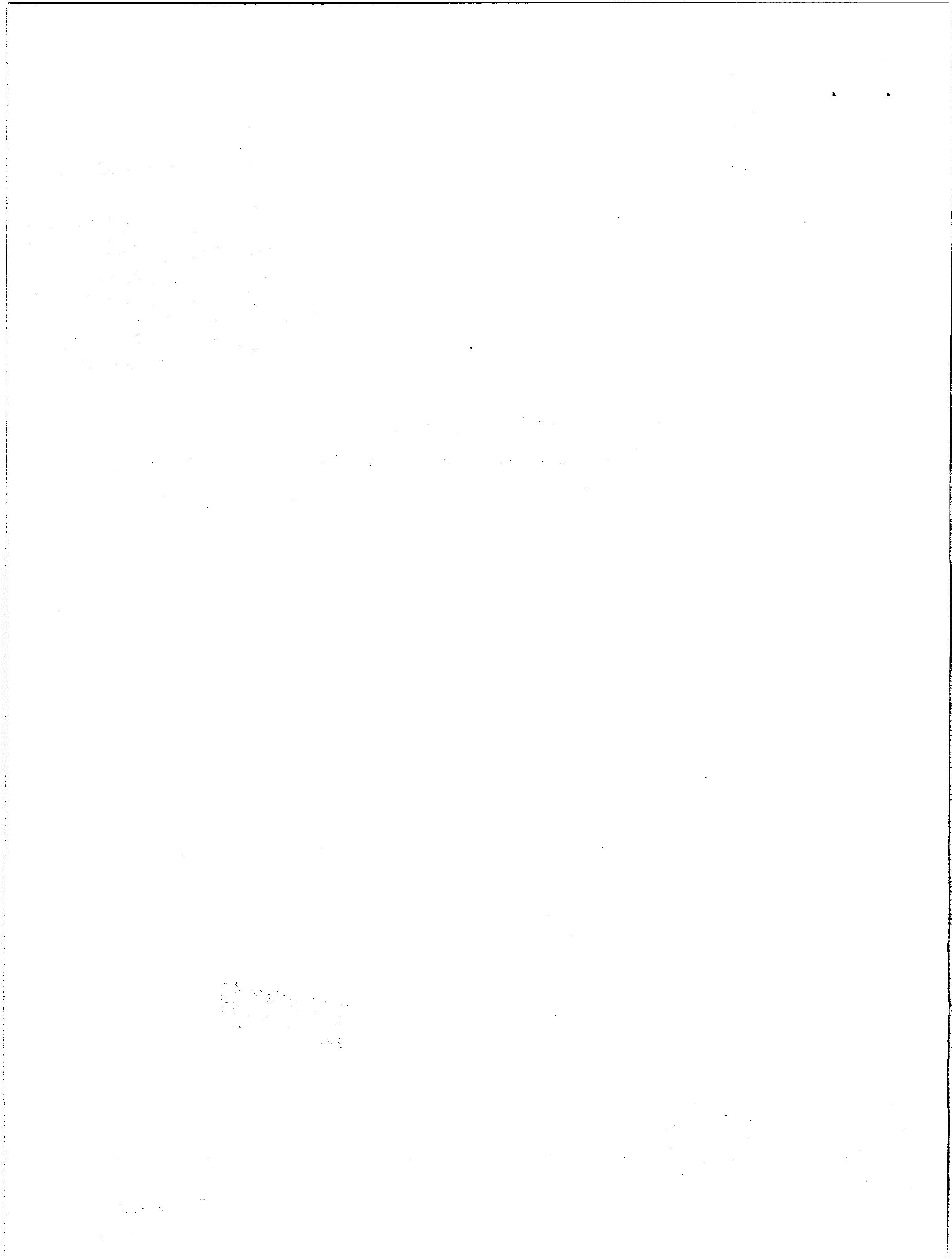


ABSTRACT

I. INTRODUCTION $\ldots \ldots \ldots \ldots \ldots \ldots \ldots \ldots \ldots \ldots \ldots \ldots \ldots$

II. THE PROGRESS OF HDR TECHNOLOGY ........... 3

III. TECHNOLOGY TRANSFER ............................ 4

A. Exploration and Resource Evaluation ....... 4

1. Geotherma1-Gradient and Heat-Flow Measurements . . 4

2. Regional Geological, Geophysical, and Geochemical

Studies .............. 5

3. Site Characterizations ........... 7

B. Drilling ................... 7

1. Slim Exploration Hole ............ 8

2. Prototype HOR System .......... 8

a. Drilling Fluids ............. 9

b. Drilling Bits .............. 9

c. Coring Bits .............. 10

d. Jarring Tools ........... 10

e. Directional Drilling ......... 10

f. Downhole Motors .......... . 11

g. Turbodrill Tachometer ............ 11

h. Float Valves .................. 12

i. Drill Guidance ........... 12

j. Cementing .................. 12

k. Sidetracking ................ 14

3. The Phase II Wells ............... 15

4. The Spallation Drill ................ 15

c. Hydraulic Fracturing ............ 16

1. Feasibility .................. 16

2. Open-Hole Packers ............ 17

3. Casing Packers .............. 18

4. Impression Packers ............ 18

5. Borehole Televiewer ............. 18 
6. Fracture Mapping . . . . . . . . . 19

a. Tiltmeters ............... 20

b. Electrical Resistivity ........ 20

c. Acoustic Emissions ......... 20 20

ก. Instrument DeveTopment .............. 21

1. Steering Tool ................ 22

2. Borehole Televiewer ........... 22

3. Geophone Sonde ............... 22

4. Detonator Tool ............. 22

5. Other Explosive Tools ........... 23

6. Crosswell Acoustic Transceiver ........ 23

7. Downhole Fluid Sampler ........... . 24

8. High-Precision Temperature Probes ....... 24

9. Hole-Surveying Instruments ......... 25

10. Fluid Injectors . . . . . . . . . 25

11. Independent-Arm Caliper Tool ....... 26

12. Spinner Tool ............... 27

E. Component Development ........... 27

1. Seals ........................ 27

2. Instrument Cables . . . . . . . . . 28

3. Cable Head ............... 28

4. Thermal Protection .......... 28

5. Electrical Connectors ......... 29

6. Motors .................. 29

7. Geophones ................. 29

8. Special Facilities ........... 29

F. Geochemistry ............ . . 30

1. Rock-Water Interactions ........ 31

2. Natural Waters ........... 31

3. Inert Tracers . . . . . . . . . . 32

4. Chemically Reactive Tracers ......... 32

5. Estimation of Fracture Aperture ....... 33 
G. Reservoir Engineering . . . . . . . . 34

1. Acoustic Fracture Mapping ......... 34

2. Seismic Signal Analysis .......... 35

3. Evaluation of In Situ Stress Field ..... 35

4. Flow in Fractured Reservoirs ........ 36

5. Spallation Drilling .......... 37

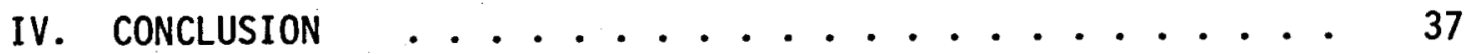

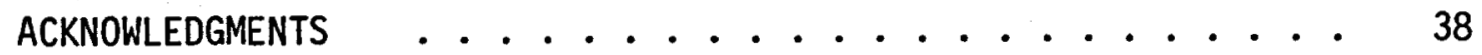


by

Morton C. Smith

\begin{abstract}
The Hot Dry Rock Geothermal Energy Development Program has focused worldwide attention on the facts that natural heat in the upper part of the earth's crust is an essentially inexhaustible energy resource which is accessible almost everywhere, and that practical means now exist to extract usefur heat from the hot rock and bring it to the earth's surface for beneficial use.

Under sponsorship of the U.S. Department of Energy and agencies of the governments of West Germany and Japan, the Hot Dry Rock Program has successfully constructed and operated a prototype hot, dry rock energy system that produced heat at the temperatures and rates required for large-scale space heating and many other direct uses of heat. The Program is now in the final stages of constructing a larger, hotter system potentially capable of satisfying the energy requirements of a small, commercial, electrical-generating power plant.

To create and understand the behavior of such systems, it has been necessary to develop or support the development of a wide variety of equipment, instruments, techniques, and analyses. Much of this innovative technology has already been transferred to the private sector and to other research and development programs, and more is continuously being made available as its usefulness is demonstrated.

It is the purpose of this document to describe some of these developments and indicate where this new technology is being used or can be useful to industry, engineering, and science.
\end{abstract}


I. INTRODUCTION

Natural heat in the rocks composing the earth's crust represents one of the largest supplies of usable energy that is accessible to man. At useful temperatures and depths that are reached routinely with conventional drilling equipment, it exists almost everywhere, and it is inherently clean energy. Since this energy already exists in the rock as heat, it is not necessary to burn a fuel or operate a reactor to produce it.

In rather unusual geologic circumstances, some of this natural heat has been transferred to deeply circulating groundwater that has then been trapped in underground "hydrothermal reservoirs" before it could return to the surface. These reservoirs of natural hot water or steam can be economical sources of energy, but -- at usefully high temperatures and usefully large fluid volumes -- they are quite rare. Except in areas where largescale earth movements have created fault zones and fracture systems, and then kept them open, the porosity, permeability, and free-water content of crustal rock all tend to decrease as depth below the earth's surface increases. This happens because increases in temperature, pressure, and rates of chemical reaction all tend to close or seal any openings in the rock that may at one time have existed. Therefore, at the depths at which rock temperatures are high enough to be commercially useful, the rock is usually "dry" -- in the sense that it contains little or no free water. This is the typical "hot dry rock" (HDR) situation and, at sufficient depth, it exists everywhere beneath the earth's surface.

In 1970, a group of scientists and engineers at Los Alamos National Laboratory suggested a method to extract useful heat from this essentially inexhaustible energy supply. It is based on the use of fluid pressure to create within the hot rock the permeability that nature has failed to provide. The operation is called "hydraulic fracturing," and it is commonly used to increase the flow of fluids into oil, gas, and water wells.

In its simplest form, hydraulic fracturing is accomplished by pumping water down from the surface into an isolated section of the well until the downhole pressure increases sufficiently to split the wall of the hole. By simply continuing to pump in water, the cracks thus produced can be extended outward into the surrounding rock for hundreds of meters, where they provide the flow passages required to circulate water over a large surface area of the hot rock.

The world's first HDR energy system was completed in 1977 at Fenton Hill in northern New Mexico, in granitic rock at a depth of around 2600 meters $\left(8500\right.$ feet) -- where the rock temperature was about $185^{\circ} \mathrm{C}\left(365^{\circ} \mathrm{F}\right)$. This "Research" or "Phase I" system was constructed by drilling a well to a depth of 2932 meters (9619 feet), producing a set of hydraulic fractures from it, and then drilling a second well to intersect those fractures. Cool water pumped down one well was heated as it circulated through the fractures and recovered through the second well as hot water under sufficient pressure to prevent boiling. It reached the surface at about $138^{\circ} \mathrm{C}\left(280^{\circ} \mathrm{F}\right)$, where its useful heat was removed and it was returned to the first well to recirculate and recover more heat. The underground system was enlarged in 1979 by additional hydraulic fracturing, and geothermal heat was produced for a total time of more than a year at rates up to 5 
million watts thermal (17 million Btu per hour). System operation was essentially trouble-free and there was no sign of scaling, corrosion, or environmental effects. It could have heated several hundred homes for many years, and some of the heat was used in a small, experimental power plant to generate electricity that was used at the site. However, most of the heat was dissipated to the atmosphere through air-cooled heat exchangers -to provide cool water for recirculation underground and recovery of additional heat.

This prototype Phase I system demonstrated the technical feasibility and environmental acceptability of producing heat at commercially useful temperatures and rates from naturally heated rock in the earth's crust. To extend the technology to greater depths, higher temperatures, and greater rates of heat production, a larger, deeper, hotter "Engineering" or "Phase II" system is now under construction at the same site. It is designed to produce heat at temperatures above $200^{\circ} \mathrm{C}\left(400^{\circ} \mathrm{F}\right)$ and rates sufficient to support generation of 5 to 10 million watts of electricity for at least 10 years.

II. THE PROGRESS OF HDR TECHNOLOGY

Almost everyone is aware that the earth's interior is extremely hot and, when the HDR Program began, considerable information was available (chiefly from deep 0 il and gas wells) about the rate at which temperature increases with depth in the earth's crust -. the "geothermal gradient." However, many questions remained concerning the variation in gradient across the United States, the nature and properties of the rock that would be encountered at depths of geothermal interest, and the technical and economic feasibility of the various operations required to create and maintain an HDR geothermal energy system. Many of these questions have since been answered in experiments and investigations at Fenton $\mathrm{Hill}$ and elsewhere, but of course new problems have also appeared and better solutions are evidently still possible to some of the old ones. Nevertheless, in the course of the HDR Program to this time, important contributions have been made to the state of knowledge of

o subsurface geology, and thermal regimes in the earth's crust;

o the equipment, instruments, and techniques needed to explore the crust and exploit its resources;

- the special characteristics of HDR thermal reservoirs;

o the methods appropriate to recovery of thermal energy from them;

- the experiments and analyses required to investigate and understand the behavior of HDR energy systems - - and of fluid-containing fractured reservoirs in general.

Much of the scientific knowledge and practical technology developed by or for the HDR Program has already been found useful both by the private sector and in other programs, and several of the developments required by and initiated in the HDR Program have been shown to have broader application and are now being continued independently el sewhere. 
Examples of the transfer and extension of HDR technology are discussed in the sections that follow.

\section{TECHNOLOGY TRANSFER}

Among the areas in which technologies developed by or for the HDR Program have been found useful by the private sector or in other programs are the following.

\section{A. Exploration and Resource Evaluation}

To justify continuing governmental support of an HDR Geothermal Energy Development Program, it was necessary to (1) demonstrate existence of an accessible U.S. resource base of thermal energy in hot, dry rock sufficient to justify active development of a practical energy-extraction technology and (2) then identify a sufficient number of locations at which a mature technology might be applied commercially to demonstrate that successful HDR systems could contribute significantly to the nation's energy future. Both requirements have been met, which has stimulated similar HDR resource evaluations in other countries around the world. Accomplishing this has involved correlating the results of a number of geological, geophysical, and geochemical investigations in a manner that has since been used successfully by industrial organizations in this country and by both industry and government agencies abroad.

1. Geothermal-Gradient and Heat-Flow Measurements. These supply the essential information required to identify and determine the extent of areas that are promising for geothermal energy development. When the HDR program began, this type of information was largely from temperaturegradient measurements in known hydrothermal areas, where temperatures were strongly affected by groundwater circulation, and from bottom-hole temperature measurements in oil and gas wells, which are concentrated in deep sedimentary basins, and in which such measurements are normally made in haste, and are notoriously unreliable. These data were collected, evaluated, and then supplemented by a broad program of field measurements across the conterminous United States.

Measurements sponsored by the HDR Program were made principally by university groups under contract to the HDR Program, with the advantages of relatively low cost, improved capabilities and increased interest in geothermal energy in the academic community, and financial support of faculty and graduate students -- some of whom have since entered the geothermal industry. However, some measurements were also made by industrial contractors and HDR Program personnel, and a free, informal, exchange of information with such organizations as the U.S. Geological Survey and State Geological Surveys brought the results of new measurements to the attention of all parties.

This activity greatly increased the data base concerning geothermal gradients and terrestrial heat flow in broad regions of the United States where they were not affected by hydrothermal or volcanic activity. It made 
possible reasonable estimates of the resource base of thermal energy contained in hot dry rock at accessible depths under the U.S., which is greater than that of fossil fuels and fissionable materials combined. It also identified promising geothermal areas across the United States - - many of them in such unexpected places as western New York and northern Nebraska.

These data have been summarized in many publications and in a published map showing conductive geothermal gradients across the conterminous United States, now in its second edition (Fig. 1). This map has been useful not only to the geothermal industry but al so to oil companies concerned with maturation of petroleum and to the military in considering the possibilities and problems of deep underground bases. However, many requests for the map have come from organizations and individuals whose reasons for requesting it are unknown, but which indicate a broad, worldwide interest in terrestrial heat flow and rock temperatures at depth.

2. Regional Geological, Geophysical, and Geochemical Studies. In addition to temperature-gradient and heat-flow measurements, a wide variety of field investigations can provide clues concerning the existence, nature, and extent of promising geothermal areas, and of the heat sources responsible for their existence. Results of such investigations are most useful when they are correlated and when anomalies possibly indicative of high temperature at depth are found to overlap or coincide. The HDR Program has used to advantage the capabilities and data of many individuals and organizations, has itself undertaken a variety of field studies to extend and improve the available information concerning regions of potential geothermal interest, and in several cases has contributed to improvement and new applications of existing exploration methods. The results have been principally published maps and papers of direct interest to the geothermal industry in particular and the earth-science community in general.

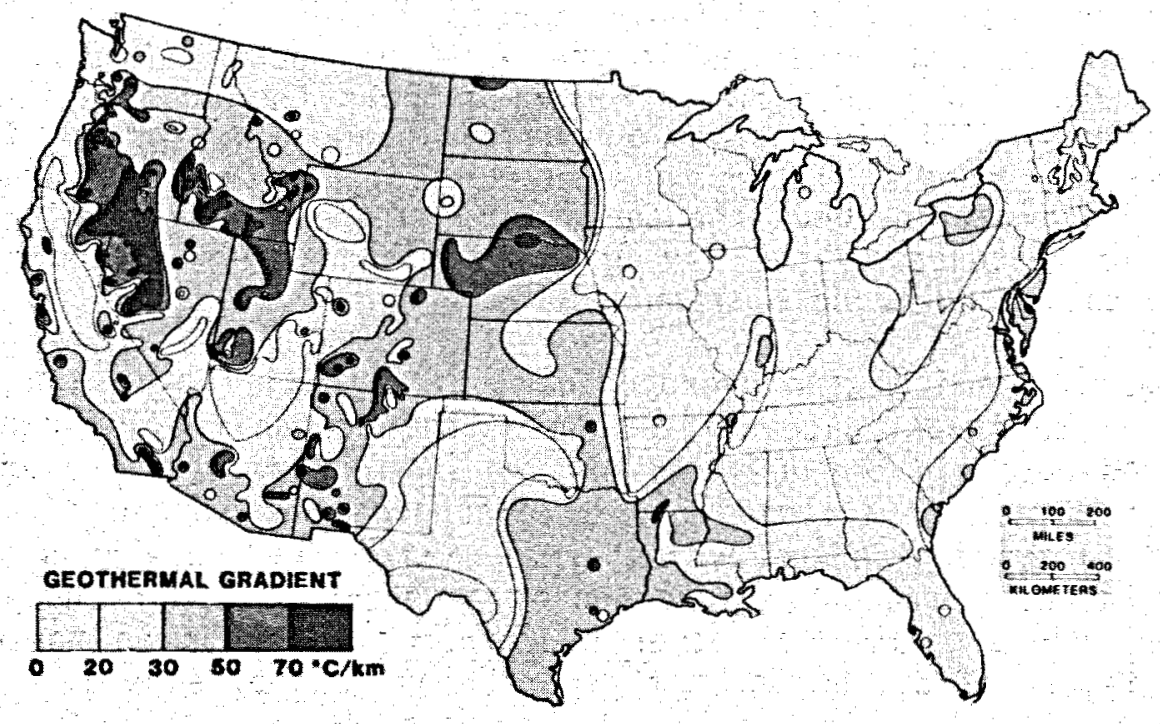

GEOTHERMAL GRADIENT MAP OF THE UNITED STATES

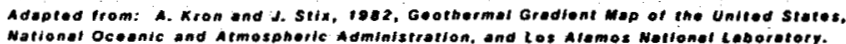

Figure 1. 
An early example of this was the use of low-sun-angle aerial photography by a consultant to the HDR Program, to examine the Fenton Hill area for unmapped faults before it was occupied for HDR experiments. This was one of the earliest applications of the technique, which takes advantage of the shadows cast by even very low surface relief when the sun is low, in order to locate the faults that have created that relief. The investigation did, in fact, identify a previously unmapped major fault in the area, fortunately at a sufficient distance from the proposed experimental site so that it did not affect operations there.

Subsequently, deep electrical-resistivity studies by another consultant confirmed the existence and location of a caldera-bounding ring fault east of the Fenton Hill site, where there was a large decrease in resistivity -- indicative of deep circulation of groundwater along the fault.

Magnetotelluric investigations in northern New Mexico and Arizona by Los Alamos personnel have established the usefulness of the method -particularly in conjunction with gravity and magnetic surveys -- as a rapid and cost-effective way to correlate heat flow with geology on a regional scale. The method involves measurements at the earth's surface of the horizontal components of the electrical and magnetic fields produced by natural electrical currents circulating in a very hot, electrically conductive layer deep in the earth's crust or upper mantle. The depth to that layer, determined by this method, correlates with the rate at which heat is conducted upward to the surface and thus with heat flow and the geothermal gradient. In general, where there is an upwelling of the conductive layer, heat flow and gradients are high. Magnetotelluric measurements therefore offer a means of locating broad areas in which the application of more localized exploration methods is appropriate, and a number of such areas have been identified in the course of this work.

A study of the orientations of faults and dikes, in conjunction with determinations of their ages, was initiated to investigate and explain the orientations of the ancient tectonic stress fields that controlled the orientations of the old fractures in the basement rock at Fenton $\mathrm{Hill}$ and the modern stress field that now largely controls the orientation of hydraulic fractures. This investigation has expanded into a broad, independent study of the stress history of New Mexico and Arizona, and it has produced new information about the formation, nature, and evolution of such major geologic features as the Rio Grande Rift, the Jemez Lineament, and the boundary of the Colorado Plateau.

Finally, geochemical and hydrologic studies initiated in the vicinity of Fenton $\mathrm{Hill}$ to investigate water supply, the probability of containment of pressurized water in the HDR heat-extraction loop, and the potential for environmental damage from fluid loss or discharge have produced important new information concerning the hydrothermal systems in and around the nearby Valles Caldera. In another independent program, this work has expanded into similar investigations of other hydrothermal systems in northern New Mexico, the island of St. Lucia in the Caribbean, and elsewhere.

These and other developments and investigations initiated by the HDR Program have broadened and improved the technology of regional resource evaluation. They have produced much new information directly useful to the 
Program itself; to the geothermal, energy, and mineral industries in general; and to increased understanding of the earth's crust and the forces that have shaped it.

3. Site Characterizations. To identify sites that are well suited to either additional HDR field experiments or to future commercial HDR development, a number of limited areas shown by regional studies to be promising for those purposes have been investigated in detail with regard to the characteristics that are important to successful creation and operation of an HDR energy system. In general, these site characterizations have been made primarily by the HDR Program staff, utilizing all information already available about the area and supplementing it with additional field and 1 aboratory work and, when necessary, with contract services by other individuals and organizations. However, two prospect areas have been investigated primarily by commercial engineering firms under contract to the HDR Program, not only to determine the potential of the areas for energy production but al so to transfer exploration and characterization techniques to the private sector and to evaluate their effectiveness when applied by private industry.

Both contracted characterizations were completed successfully, and both produced a great deal of useful new information concerning the geology, geophysics, and thermal regimes of the areas studied. One, on the East Coast, demonstrated the probable suitability of an area on the Delmarva peninsula of Delaware, Maryland, and Virginia for HDR development to produce heat at temperatures appropriate for space heating, food processing, and other relatively low-temperature direct uses. The other, in Southern Idaho, demonstrated that certain published geologic information concerning an area on the north edge of the Snake River PI ain was incorrect and that, in fact, that particular area was not suited to development of a high-temperature HDR system for generating electricity. More promising locations have been identified and characterized el sewhere.

The results of all of these investigations have been published and made fully available to the geothermal industry and the earth-sciences community. One very important conclusion from the se and related studies (for example, detailed examinations of the interiors and surroundings of old plutons that have been dissected by erosion) is that in general, even in high-grade hydrothermal areas, more than $95 \%$ of the heat is present in the rock itself rather than in any fluid contained in or circulating through the rock. This provides an incentive for the owners of hot, dry wells anywhere - - within or around the hydrothermal areas, together with dry exploratory holes el sewhere - to keep those wells open until HDR technology can make them into energy producers.

B. Drilling

Every stage of a geothermal energy development involves drilling, from shallow heat-flow holes in the exploration phase to well repair and replacement during energy production. As the holes required get larger, deeper, and hotter, and especially when they require directional drilling, 
they become progressively more difficult and expensive to complete, and drilling finally represents a major fraction of the total cost of a geothermal operation.

Except for the initial temperature-gradient holes, which were only about 30 meters (100 feet) deep and were drilled with a Los Alamos soil-sampling rig, all drilling in the HDR Program has been done by commercial drilling contractors, with field support by oil-field service companies and planning and supervision by HDR staff and consultants to them. The deeper heat-flow holes, each about 150 to 230 meters $(500$ to 750 feet) deep, were drilled and cored by a truck-mounted rotary prospecting rig. Two holes about 580 meters (1900 feet) deep, for emplacement of geophones, were subsequently drilled by a truck-mounted cable-tool rig. In all of these cases, the equipment and operations were quite conventional. That, however, was not true of the drilling of five deeper holes, the last four of which have required development of special equipment and techniques that have since been found useful in geothermal operations elsewhere and in drilling hot oil and gas wells.

1. Sl im Exploration Hole. In June 1972, the first deep exploratory hole in the HDR Program (well GT-1) was drilled to a final depth of 785 meters (2575 feet) by a truck-mounted, rotary, uranium-prospecting rig. It penetrated 143 meters (470 feet) of crystalline basement rock, reaching a bottom-hole temperature of $100.6^{\circ} \mathrm{C}\left(213^{\circ} \mathrm{F}\right)$. Contrary to the predictions of several drilling experts, this demonstrated that hot, hard, abrasive, crystalline rock could be drilled successfully with conventional rotary drilling tools.

The section of hole in the basement rock was drilled and cored at a diameter of 11.4 centimeters ( 4.5 inches). The small hole-diameter facilitated a successful series of hydraulic-fracturing experiments in which short, uncased sections that were to be pressurized were isolated between open-hole packers (elastomeric seals expanded against the wall of the hole). This was the first demonstration of the usefulness of such packers for stimulating a geothermal well. It also demonstrated -- again contrary to the predictions of certain experts -- that hot, crystalline rock could indeed be fractured by fluid pressure and that (at least in this particular location) it did not contain open fractures through which fluid would be lost at a high rate. Permeability of the basement rock was found to be extremely low.

Inflatable impression packers, described in a later section of this report, were used to examine rock structure and the nature and orientation of the hydraulic fractures. This was their first use in a geothermal well.

This was also the first demonstration of the economy and experimental advantages of drilling a slim exploratory hole in the early stages of exploration of a geothermal area.

2. Prototype HDR System. The two wells of the prototype (Phase I) HDR system described above were drilled in 1974 and 1975, well GT-2 to a depth of 2932 meters (9619 feet) and well EE-1 to 3064 meters $(10,053$ feet) 
-- where the rock temperature was $206^{\circ} \mathrm{C}\left(402^{\circ} \mathrm{F}\right)$. The lower part of well GT-2 was subsequently directionally redrilled twice to improve its connection to a system of hydraulic fractures that had been produced from the other well.

This was the first extensive drilling ever done in very hot granitic rock and probably the first time that wells had been sidetracked (for redrilling along a new trajectory) or directionally drilled in such a formation. While the drilling was completed successfully, the problems encountered required technological developments that have since proved useful to the geothermal industry in general and in such other operations as the drilling of hot natural-gas wells in the overthrust belt of the western United States.

a. Drilling Fluids. Support of the borehole wall is not ordinarily necessary in competent crystalline rock, eliminating the need for a high-density drilling fluid. Therefore, once the overlying volcanic and sedimentary rocks had been penetrated and the hole cased through them, drilling in the basement rock was normally done with a clear-water circulating fluid instead of mud. This was a major and very successful departure from conventional drilling practice. It saved the high cost of the mud and the constant attention by technical personnel needed to control its composition and properties, and it avoided contamination and possible plugging of existing fracture zones. However, while the higher viscosity of mud relative to water reduces its effectiveness in cooling the hole and the drilling tools, it increases the ability of the circulating fluid to lift coarse cuttings from the bottom of the hole. This improves hole cleaning and reduces overgrinding of the cuttings, which tends to increase penetration rate. The coarse cuttings are better samples for the site geologist to examine for rock type and the presence of unexpected minerals or alteration products. The sepiolite mud used in recent redrilling of one of the deep wells at Fenton Hill appears also to increase lubricity of the drilling fluid, reducing wear on drilling assemblies and increasing bit life. All of this may compensate or more than compensate for the high cost of the mud, although the potential for plugging existing fractures remains a problem.

A 1 imited amount of drilling was done with air instead of water or mud, and - contrary to a common belief - - it was found that drilling with water instead of air resulted in a small increase in penetration rate. It was also found that the more effective cooling provided by water reduced bit wear, corrosion, and mechanical trouble with downhole tools, and that lifting the cuttings out of the hole with water instead of air greatly reduced the rate of erosive wear on the outside of the drill pipe.

b. Drilling Bits. Drilling in hot, hard, abrasive rock generally involves low penetration rates and relatively short bit lives. Comparative tests during drilling of the Phase I wells suggested several ways in which the carbide-insert, three-cone, roller bits normally used in hard-rock rotary drilling could be improved. Working with a commercial bit manufacturer and testing its bits at Fenton Hill, the HDR Program assisted in development of an improved geothermal bit that incorporated better 
bearings in the roller cones, harder carbide inserts -- especially in the gauge (outside) rows on the cones -- and wear protection on the legs and skirt of the bit provided by hard facing and carbide inserts there. The higher cost of these special bits is more than balanced by their improved performance, and they are now widely used throughout the geothermal industry.

c. Coring Bits. To examine the nature, structure, and properties of the rock being penetrated, cores are recovered from the hole in many exploratory drilling operations. These are cylindrical samples of the rock, normally drilled out by use of hollow cylindrical diamond bits. However, these bits are very expensive, and early in the HDR Program it was determined that -- in the crystalline basement rock at Fenton $\mathrm{Hill}$-- their penetration rates were very low and their useful lives were very short. Working with their manufacturers, the HDR Program assisted in the development of improved diamond coring bits for use in this very hard, abrasive rock.

However, the HDR Program also undertook the first use on 1 and of a four-roller-cone coring bit originally developed for the deep-sea (JOIDES) drilling program and worked with its manufacturer to improve it for use in this type of rock. The improved hybrid coring bit, now a commercial product, retains the basic carbide-insert, four-cone design but includes rigidly mounted, synthetic-diamond cutters to dress the core surface. At Fenton Hill it has given higher penetration rates and longer life than even the improved conventional diamond bits, at lower cost per foot of core recovered.

d. Jarring Tools. When drill pipe or drilling tools are stuck in the hole, as much as possible of the pipe above the stuck point is detached and removed from the hole; a jarring tool is inserted at the end of the pipe that has been removed, which is then reinserted and attached to the pipe that was left in the hole; and, by means of the jarring tool, impact is applied to the stuck lower section to loosen it so that it too can be removed. Tools of this type are a standard item of drilling hardware and are used frequently - - usually with good results. In addition to these "fishing jars," "drilling jars" are commonly included in the bottom-hole drilling assemblies used at Fenton Hill.

The HDR Program worked with two manufacturers to develop hydraulically actuated jarring tools that would operate reliably at temperatures above $200^{\circ} \mathrm{C}\left(400^{\circ} \mathrm{F}\right)$. Both companies now market those tools.

e. Directional Drilling. The directional drilling and redrilling required to complete the Phase I heat-extraction loop at Fenton Hill apparently was the first ever attempted in hot crystalline rock. It was accomplished successfully, but only after overcoming a variety of problems that demonstrated a need for new equipment and techniques of several types. With the resulting improvements in high-temperature, hard-rock drilling technology, the deeper, hotter wells of the Phase II system were 
directionally drilled with precise control of both inclination and azimuth. Much of this technology is now widely used by the private sector.

f. Downhole Motors. To make controlled directional changes in a hole being drilled requires the use of a downhole motor attached to the end of the drill pipe through a "bent sub" - a short section of drill pipe that is permanently bent through a small angle. The downhole motor rotates the drill bit, making it unnecessary to rotate the drill pipe and thus making it possible to keep the bent sub pointed in the direction in which it is desired to deviate the hole. These motors are driven by drilling fluid pumped down the drill pipe and, since that fluid is usually a drilling mud, they are commonly called "mud motors."

Typically, a mud motor is a positive-displacement motor in which the stator is an elastomer that alternately is compressed by and expands against the rotor that turns the drill bit. In the directional drilling required to complete the Phase I system, it was found that, as the rock temperature approached $200^{\circ} \mathrm{C}\left(400^{\circ} \mathrm{F}\right)$, the elastomer deteriorated rapidly and the life of the motor became very short. This provided an incentive for the manufacturers of mud motors to increase the temperature capabilities of their motors by using higher temperature elastomers and improved seal and bearing designs. The improved motors are now widely used wherever directional drilling is required.

However, none of the available elastomers suitable for this application can be expected to survive downhole temperatures above about $250^{\circ} \mathrm{C}$ $\left(500^{\circ} \mathrm{F}\right)$, and temperatures considerably higher than that were expected in the Phase II wells. The HDR Program therefore sponsored and participated directly in the development and testing of a geothermal Turbodrill -- a fluid-driven, all-metal turbine for downhole use at high temperatures. Prototype Turbodrills were used successfully in drilling the Phase II wells at depths approaching 4270 meters $(14,000$ feet) and rock temperatures above $300^{\circ} \mathrm{C}\left(570^{\circ} \mathrm{F}\right)$. This was the first application of the Turbodrill, and it involved development of operating procedures for its effective use. High-temperature Turbodrills are now manufactured in both the United States and Japan, and they have been used successfully in both countries -- and several others.

g. Turbodrill Tachometer. In cooperation with the Turbodrill manufacturer and with the Department of Energy's Morgantown Research Center and the Sperry Research Center, a fluid-pulse tachometer was developed to measure the rotational speed of the Turbodrill while it was operating downhole. Approximately $40 \%$ of the first stage of both the turbine-inlet rotor and stator were blanked off so that, with each rotation, a pressure pulse was created that was transmitted to the surface through the fluid column in the drill pipe. Pressure desurgers were added to the pump-outlet flow lines to reduce pressure fluctuations caused by the rig pumps. With this addition, pressure pulses produced by turbine rotation and detected with pressure transducers on the standpipe flow-line could be processed with a fast spectrum analyzer to determine the rotational rate of the turbine rotor. The system was tested and used during directional drilling of well EE-2 at Fenton Hill, and it performed very well at depths slightly in excess of 3050 meters $(10,000$ feet $)$. 
h. Float Valves. A float valve is a one-way valve inserted in the drill string just above the bit to prevent back-flow of the drilling fluids and rock cuttings up the drill pipe. During drilling of the Phase I wells, repeated failures of the float valves caused frequent plugging of downhole motors and drill collars by cuttings carried upward into them. This was found to result from the failure of the elastomeric seals on the valves. Working with the manufacturer, the HDR Program tested a variety of higher temperature elastomeric seals in a high-temperature autoclave at Los Alamos National Laboratory. An EPDM formulation developed by another company (also under sponsorship of the U.S. Department of Energy) was found to perform successfully at the required temperatures and pressures, and float valves equipped with EPDM seals have since been used successfully in the hotter Phase II wells.

i. Drill Guidance. The reaction forces developed as a drill bit is rotated against the rock cause the drill pipe to twist elastically in the opposite direction -- through as much as several complete revolutions if the hole is deep and the load on the bit is high. These forces cause the bent sub to rotate away from its original position as load is applied to the bit, to a degree determined by the load on the bit, its condition, the torsional stiffness of the assembly, and the properties of the rock being drilled. This in turn causes the bit, while it is actually drilling, to be pointed in a direction that may be quite different from that into which it was intended to direct the hole. From the torque on the bit measured at the rig floor and the length and type of drill pipe in the hole, the driller can estimate the orientation of the bit, but the uncertainty in this estimate is very large. For precise control in directional drilling, a downhole "steering tool" is needed. This is an instrument lowered through the drill pipe into an orienting sleeve just above the downhole motor, which sends to the surface an electrical signal that continuously indicates the inclination and azimuthal orientation of the drilling tools as drilling proceeds.

During the directional drilling required to complete the Phase II system, several different steering tools were tried. Only one of them approached the capabilities to withstand the severe conditions of shock, vibration, and temperature encountered as the hole was deepened. This experience led the service company that produced the tool to improve it, particularly with regard to its protection against high temperatures. The HDR Program assisted in this by suggesting design changes and field-testing the improved tool in the Fenton Hill wells, and it was used successfully in directionally drilling the very deep, very hot holes of the Phase II system. This tool is now widely used in geothermal and other hot-hole drilling around the world. Further, to meet this competition, at least two other companies have now similarly improved their own steering tools.

j. Cementing. This is often necessary at several stages of drilling, well completion, repair, or abandonment -- to seal "lost circulation zones" where drilling fluid is lost from the well into the formations around it; to seal the annulus between well casing and the borehole wall; to close breaks or perforations in the casing; to provide a solid base at the desired depth in the well to facilitate a "sidetracking" operation -- in which the lower part of the hole is redrilled to bypass stuck tools or 
follow a new trajectory; or to seal off the lower part of the hole temporarily or permanently. In any of these operations, the rate at which a cement "sets up" and hardens, and its final properties, depend jointly on the formulation used, the temperature to which it is exposed, and the rate at which the cement warms to that temperature or the rock temperature around it changes.

Cement chemistry is very complex and is not yet fully understood. This was demonstrated repeatedly during drilling of the Phase I wells at Fenton Hill. In one case the cement set up prematurely within the drill pipe as it was being pumped down the hole; in another case it set up around the drill pipe before the pipe could be raised, freezing it in place; and in several cases it did not set up at all or remained very soft. The HDR Program therefore initiated a 1 imited program of research on cements, which included both modeling and direct measurements of temperature changes that occur in a hot well as it is cooled by fluid circulation, during emplacement of cement, and while the cement hardens; cement formulations, and their reactions under these varied conditions of temperature and temperature change; and the structures and properties of the hardened cements. This work was done in close cooperation with experts from two major companies that provide we1l-cementing services, and the new information developed was shared freely with them.

After the components of the cement formulation have been thoroughly mixed and a uniform cement slurry has been prepared, the cement must be properiy emplaced in the well. This is done by pumping the slurry down drill pipe to the desired depth, followed by sufficient water to displace the cement from the drill pipe. In addition to difficulty in controlling the setup time of the cement, common problems include contamination of the slurry by mud and cuttings left in the hole and -- especially -- by mixing with the water that precedes and follows it; and overdisplacement of the cement (pumping in so much water behind it that the slurry flows on beyond the region in which it was intended to place it). In the Phase II drilling and completion operations, contamination of cement slurries posed a very difficult problem, in part, probably, because of the reduced density and viscosity of water at high temperatures.

In cementing in oil and gas wells, contamination is usually controlled by pumping down a large excess of slurry and circulating water to fiush out the first ("lead-in") and last ("tail-in") fractions of the slurry, leaving the uncontaminated intermediate part in place. This is a high-risk operation in a very hot well because of the strong interaction of temperature with the precise amount of chemical retarder that must be added to the slurry to prevent premature setting. Instead, at Fenton Hill, wiper plugs were used to reduce contamination of the slurries. These are loose, drillable, metal plugs surrounded by an elastomeric sealing element, which are usually pumped down the pipe immediately behind the cement, to separate it from the displacement fluid that follows the cement. The wiper plug is finally caught by a retainer near the end of the drill pipe, which is expected to result in a sudden increase in pumping pressure -- indicating to the operator that the cement has been completely displaced from the pipe. Viton wiper plugs were used successfully in this way in the Phase II wells at Fenton Hill and, while they reduced contamination, they did not eliminate it. Two tests were therefore run using a double-plug technique 
in which a second wiper plug immediately precedes the cement and is sheared mechanically when it reaches the retainer. Although some contamination still occurred due to bypass of fluid around the upper plug, the technique was successful and produced substantially harder cement than when a single wiper plug was used.

Unfortunately, EPDM seals on the plugs -- which were succesful in static tests -- were found to separate from the aluminum body of the plug during a cementing operation at above $260^{\circ} \mathrm{C}\left(500^{\circ} \mathrm{F}\right)$ in one of the deep Fenton Hill wells. A cooperative program has therefore been initiated to further improve wiper plugs.

The "bump" of a wiper plug when it encounters the retainer is often not detected at the surface. It is therefore important to know precisely the volume of displacement fluid that should be pumped in order to displace the cement from the drill pipe without overdisplacing it. In a very hot well, calculation of the proper volume is complicated by thermal expansion of the fluid as it moves down the pipe. The WBHT (Wellbore Heat-Transfer) code developed by the HDR Program has been used with increasing accuracy during Phase II operations to calculate the proper displacement vol ume, and no overdisplacement has occurred during Phase II completion operations.

k. Sidetracking. When it becomes necessary to drill out through the wall of an existing hole to avoid stuck drilling tools that cannot be recovered or to reach a different part of the reservoir formation, it is usually done in petroleum and natural-gas wells by emplacing a cement plug at the desired sidetracking depth, then using a downhole motor with a bent sub to force the bit against the wall of the hole. In the relatively soft sedimentary formations encountered in most oil and gas wells and some geothermal areas, this technique is used frequently and usually with a minimum of trouble. However, when it was first attempted in the crystalline basement rock at Fenton Hill, it was unsuccessful; the rock was so much harder than the cement that the drill bit simply slid down along the wall of the hole instead of cutting into it. Working with their manufacturer, specially designed side-cutting diamond bits were developed. The hole was underreamed to provide a ledge for the edge of the bit to bear upon and, using those bits, sidetracking was finally accomplished. In a second sidetracking operation, at greater depth and out of the low side of an inclined hole, success was achieved in a much shorter time without underreaming and using a carbide-insert three-cone bit instead of an expensive diamond bit. (This was probably facilitated by the presence of a natural joint that crossed the wellbore at that depth.)

However, when -- on two occasions -- it was necessary to sidetrack one of the deeper wells of the Phase II system, repeated attempts using either diamond or roller-cone bits, with and without underreaming, were unsuccessful. In both cases, it was finally necessary to use a whipstock -- a sharply tapered cast-steel wedge anchored in the hole, whose sloping upper surface forces the descending drill bit firmly against the wall of the hole.

This sidetracking experience, which is widely known from publications of the HDR Program, will encourage other drillers to save time and money by 
going directly to the whipstock technique when a hole must be sidetracked in very hard rock.

3. The Phase II Wells. The two wells of the Phase II system at Fenton Hill were drilled to vertical depths of 4389 meters $(14,400$ feet) and 3977 meters $(13,049$ feet), each penetrating more than two miles of crystalline basement rock. The bottom 1000 meters (3000 feet) of both wells were drilled at an angle of $35^{\circ}$ to the vertical, with the inclined section of the shallower well about 380 meters (1250 feet) vertically above that of the deeper wel1 - - which reached a bottom-hole temperature of $327^{\circ} \mathrm{C}$ $\left(620^{\circ} \mathrm{F}\right)$.

To produce that well geometry required a degree of precision in directional drilling seldom before attempted, with continuous control of both inclination and azimuth of the second hole to maintain its position relative to the first one. This was accomplished in extremely hot, hard, abrasive rocks, at the greatest depths that had to that time been reached by geothermal wells. The materials, equipment, and techniques developed to drill the Phase I wells were used in full, and in several cases were improved significantly.

All of this technology has been made freely available to the geothermal community and the drilling industry in general, and much of it is now being used around the world. Its most direct transfer was to the British HDR Program in Cornwall, where a well configuration similar to that of the Phase II system at Fenton Hill has since been produced quickly and with no major problems -- although at shallower depths and much lower temperatures.

4. The Spallation Drill. In general, drilling represents about one-half of the total cost of a geothermal development, and a significant reduction in drilling cost would therefore have a large positive effect on the economics of geothermal energy production - and al so of many other industries that require deep holes in the earth's crust. The need for this cost reduction is widely recognized, and a broad variety of unconventional drilling methods have been proposed that might in some cases accomplish it. One of the most promising of these is spallation drilling.

Spalling occurs when the surface of a dense, brittle rock is heated rapidly, causing a thin surface layer to expand against the restraint of the cooler rock beneath it, and finally to break free from it as thin flakes or slabs - called "spalls." The relatively soft, somewhat porous sedimentary rocks commonly penetrated in oil and gas fields resist spalling (but are quite readily drilled by conventional methods). However, hard, dense, abrasive rocks - - such as the granitic basement rock at Fenton Hill - which are more difficult to drill mechanically, in general spall quite readily. Flame-jet spallation drills have already been developed by others to take advantage of this and are used commercially to drill blast-holes in taconite iron mines and to quarry granite - - where their penetration rates are very high and their per-foot drilling costs are low. Unfortunately, 
with present designs, the depth capabilities of these drills are very limited, and of course drilling would stop if the hole encountered rock that would not spall.

Most HDR systems of the Fenton Hill type will probably be developed in crystalline rock that spalls readily, in which the high penetration rates and relatively low cost of spallation drilling would be major advantages. However, the holes required to reach the hot crystalline rock will normally be far deeper than the present depth capacity of spallation drills, and they must usually penetrate considerabie thicknesses of non-spaliable volcanic or sedimentary rock before they reach the crystalline basement.

A preliminary study initiated in the HDR Program indicated that it should be possible to develop a spallation-drilling unit that could be used with a conventional rotary drilling rig, retaining the capability of the rig to drill through non-spallable rocks mechanically but also permitting quick conversion to spallation drilling when spallable rocks were reached. A conceptual design of such a unit has been developed, and a small drilling rig was modified to investigate the concept of spallation drilling by means of a flame-jet burner lowered on standard drill pipe or through seals in conventional well casing. Field tests with this experimental rig in exposed granite in central New Mexico were very successful. This led to establishment of a separate Spallation Driliing Program to undertake further development of the components required to complete a system that would be directly usable on a commercial rotary drilling rig.

In addition to high penetration rates and low per-foot drilling costs in spallable rocks, the spallation drill has a unique capability to produce very large-diameter holes or caverns -- simply by reducing the rate at which the burner moves along the hole. It therefore has the potential to produce large shafts and underground chambers for storage of compressed air, natural gas, liquid fuels, hot water, or hazardous wastes.

\section{Hydraulic Fracturing}

This operation is basic to creation of the type of heat-extraction system being developed at Fenton Hill, and, before the HDR field program began, it apparently had never been attempted in hot, crystalline rock. To accomplish it successfully at high temperatures in a large-diameter geothermal well has required a number of developments, several of which have al ready found use in geothermal-well stimulation and in steam-flooding for tertiary recovery of petroleum.

1. Feasibility. In early discussions of the HDR concept, before field work was undertaken, one expert opinion collected from outside the Laboratory was that hydraulic fracturing would be impossible in hot, crystalline rock. In fact, in the slim exploratory hole described above, a series of hydraulic fractures was produced with no major difficulty in granitic rock at depths around 760 meters $(2500$ feet) and temperatures near $100^{\circ} \mathrm{C}\left(200^{\circ} \mathrm{F}\right)$. Pumping pressures required were less than 14 million Pascals (2000 pounds per square inch), and rather primitive equipment -acquired from salvage or borrowed from other programs -- was used successfully by untrained operators. 
Since then, in a long series of experiments in the Fenton Hill wells, large hydraulic fractures have been produced at progressively greater depths and higher temperatures. The extreme case was hydraulic fracturing at a depth of 4270 meters $(14,000$ feet $)$ and a rock temperature of about $315^{\circ} \mathrm{C}\left(600^{\circ} \mathrm{F}\right)$, which required a pumping pressure of 33 million Pascals (4800 pounds per square inch), still easily attainable by conventional service-company pump trucks.

These results caused the U.S. Department of Energy to initiate a separate Geothermal Well Simulation Program, in which - with strong industrial participation - the use of hydraulic fracturing to increase the flow of geothermal fluids into geothermal wells was successfully demonstrated. It is bel ieved that this type of well stimulation may become as common in geothermal fields as it is now in oil and gas fields.

2. Open-Hole Packers. Several methods are available to isolate a particular section of a borehole to permit pressurization of only that part of the hole in which it is desired to produce a hydraulic fracture. In an uncased well, the most convenient of these is the use of open-hole packers, in which an elastomeric sleeve is expanded to press against the wall of the hole and temporarily seal the opening between it and the solid body of the packer -- much as a rubber stopper seals a tube or bottle.

Commercially available open-hole packers were used successfully in the HDR Program's first hydraulic-fracturing experiments in the small-diameter exploratory wel1. However, at the progressively higher temperatures encountered in the Fenton Hill wells, softening and degradation of the elastomeric sealing el ement progressively reduced the sealing capability of the packers, and the forces that they were required to resist were greater -- both because hydraulic-fracturing pressures were higher and because, in the larger diameter holes, the area of the packers on which those pressures were exerted was greater. To increase their temperature and pressure capabilities, the HDR Program sponsored the first commercial development of high-temperature open-hole packers for use in geothermal wells. Three manufacturers have been involved, who produced open-hole packers of distinctly different mechanical design, and each has improved its product to the point at which it closely approaches the requirements of the Program. However, some further increase in capability is still needed, and so this activity is continuing. A recent and very promising development is an inflatable packer in which fluid pressure expands a specially designed elastomeric sealing element against the wall of the hole. At one end, the elastomer is overlaid by a series of closely spaced, curved, stainless-steel strips which are pressed against the rock, anchoring the packer firmly in place. A prototype packer of this type was recently used successfully in a Fenton $\mathrm{Hill}$ well to produce a small hydraul ic fracture at $200^{\circ} \mathrm{C}\left(400^{\circ} \mathrm{F}\right.$ ), with a differential pressure of 31 million pascals ( 4500 pounds per square inch) across the packer. In a second test using a large expansion joint above the packer, approximately 285 cubic meters 175,000 gallons) of water were pumped through it, achieving a very large cooldown, before thermal contraction caused the packer to move suddenly up the hole. However, the packer resealed there and another 285 cubic meters $(75,000$ gallons) of water were then pumped before a leak through the formation terminated the test. These two tests have provided valuable information 
for an improved design of a new inflatable open-hole packer, which is now being developed.

In the meantime, the high-temperature open-hole packers previously developed are already being used by the private sector in a variety of commercial applications.

3. Casing Packers. These seal against the smooth inner surface of a steel well casing instead of the relatively rough rock wall of an uncased hole, and are widely used for a variety of purposes in oil, gas, and water wells. At Fenton Hill, they have been used primarily for hydraulic fracturing, by emplacing them near the lower end of the well casing or a liner (a short length of casing cemented into the open-hole section) in order to confine pressurization to the open-hole section below the steel pipe. However, the high temperatures encountered have caused problems with both the elastomers and the mechanical operation of the packers. The HDR Program has therefore assisted three manufacturers to increase the temperature capabilities and mechanical design of their casing packers, and the improved packers have since been used successfully in the Phase II wells at differential pressures up to 35 million Pascals (5000 psi) at temperatures above $230^{\circ} \mathrm{C}\left(450^{\circ} \mathrm{F}\right)$. These packers are now available commercially and will be especially useful in stimulation of hydrothermal wells.

4. Impression Packers. One way to inspect the inner surface of a wellbore is by the use of impression packers. These are packers covered by a soft elastomeric sleeve that is inflated by fluid pressure to press against the wall of the hole, held there briefiy, then collapsed, brought to the surface, and inspected for the impressions that represent fractures or other surface features on the borehole wall.

The first use of impression packers in a geothermal well was in the slim exploratory well, where they showed that the hydraulic fractures produced were substantially vertical and crossed the borehole in a roughly northwest-southeast direction. Subsequently, in one of the Phase I wells, an impression packer was used below an open-hole packer to measure the width of a pressurized hydraulic fracture.

Unfortunately, at greater depths and higher temperatures, the soft elastomer tended to stick to the wall of the hole and remain there when the body of the packer was brought to the surface. However, a series of experiments showed that the high-temperature open-hole packers described above retained a good impression of the borehole wall and could be used as impression packers at temperatures above those at which the conventional impression packers failed.

5. Borehole Televiewer. At best, impression packers are expensive to use (because of the rig time required for each round trip into and out of the hole) and, with each trip, they produce a relief map of only a few feet of the borehole wall. An intensive effort is therefore being made to develop a high-temperature borehole televiewer -- an acoustic instrument 
that allows a continuous scan of the entire borehole wall, measuring the dimensions of the hole so precisely that the measurements can be converted to a detailed image of its inner surface. The image can be used to determine the location, nature, and orientation of natural or hydraulic fractures, to inspect damaged casing, or to examine any other feature that produces surface relief on the wall of the hole.

As a televiewer is raised or lowered in the well, it alternately emits a high-frequency sound wave and detects its reflection from the borehole wa11. A precise measurement of the time required for the sound to reach the wall and return represents a distance measurement sensitive enough to reveal the presence of even very thin cracks. The amplitude of the reflected wave depends on the roughness and inclination of surface features, so that the returning signals can also be processed to produce something very like a photograph of the borehole wall.

Televiewers for use at near-atmospheric temperatures have been available commercially for about 15 years. The first attempt to protect such an instrument against high temperatures was made by the U.S. Geological Survey, whose prototype televiewers were tested successfully at Fenton Hill and used by the Survey in a number of other geothermal wells. Sandia National Laboratories has since developed the instrument further and improved signal processing to produce a much better image. Its instrument has also been tested successfully at Fenton Hill and (with the assistance of an HDR Program field crew and logging truck) in hydrothermal wells in California.

In a joint program with Westfalisch Berggewerkschaftskasse (WBK), a West German company, the HDR Program at LOS Alamos has also undertaken development of an improved high-temperature borehole televiewer, with electronic, acoustic, and mechanical features somewhat different from the Sandia and Geological Survey instruments. In particular, it is housed in a modular instrument package, to facilitate assembly, disassembly, and repair in the field; has a forward-mounted transducer assembly; and incorporates a downhole microprocessor that converts analog to digital signals for transmission to the surface - avoiding the attenuation and distortion that occur when the analog signals go directly to the surface through an instrument cable. At the surface, the display, recording and control functions are performed by another microprocessor, which el iminates the requirement for continuous attention by a highly skilled operator. The downhole instrument has a dual-frequency capability, with the desired signal frequency selected at the surface.

The Los Alamos/WBK borehole televiewer should be fully tested and ready for routine downhole use by the end of 1985 .

6. Fracture Mapping. Impression packers and the borehole televiewer produce useful information about the height and orientation of a hydraulic fracture as it enters the borehole wall, but they cannot observe the changes in its azimuthal orientation, inclination, and dimensions that occur as it grows out into the reservoir rock. So that it can be intersected by another directionally drilled wellbore at a location such 
that fluid circulation will extract heat efficiently, it is important that its location, size, and shape be known accurately at large distances from the well from which it was produced.

When the HDR Program began, calculations and the results of a few experiments done el sewhere indicated that any of three effects might be useful in learning something about fracture orientation and dimensions away from the borehole, before a second well was drilled to intersect the fracture.

a. Tiltmeters. The increase in volume and pressure at depth when a hydraulic fracture is inflated by fluid pressure should cause a slight upward bulging of the earth's surface above the fracture, which might be barely detectable as a change in inclination along the edges of the bulge. To investigate this, an array of very sensitive tiltmeters was installed around the first well of the Phase 1 system and monitored during hydraulic-fracturing experiments in that well. No indication of a change in slope was detected, and it was concluded that the technique would be useful only if the fractures were much closer to the earth's surface than will usually be the case in HOR systems.

b. Electrical Resistivity. The formation of a water-filled crack within it would be expected to greatly reduce the electrical resistance of the reservoir formation, especially in the direction parallel to the crack. However, a network of stations around the Fenton $\mathrm{Hill}$ site during hydraulic fracturing in a Phase I well failed to detect any changes in electrical resistivity at depth. Like the volume change accompanying fracture inflation, the effect apparently was masked by a thickness of several thousand feet of volcanic, sedimentary, and crystalline rocks between the fracture and the earth's surface.

c. Acoustic Emissions. As a hydraulic fracture is extended, it does not grow smoothiy and continuously, but instead by a series of small fracturing events distributed around its periphery. These actually are microearthquakes, which produce ground motions with amplitudes that are generally less than one one-thousandth of that of the smallest natural earthquake that can be felt at the earth's surface. However, experiments at Oak Ridge National Laboratory had demonstrated that these tiny events could be detected and mapped using very sensitive seismometers at the surface and the techniques of conventional seismology.

In the first attempts by the HDR Program to apply this technique, a single sensitive geophone was frozen into the ground near the wellhead during a wintertime hydraulic-fracturing experiment at about 760-meters (2500-feet) depth in the slim exploratory hole. Only one event was recorded that appeared to represent hydraulic fracturing. However, this was sufficiently encouraging that an array of geophones was installed around the Fenton Hill site and monitored during hydraulic-fracturing experiments in the Phase I wells at depths between about 2400 and 3000 meters $(8000$ and 10,000 feet). No signals associated with fracturing events were detected by this array or by either a geophone emplaced in the 
exploratory hole about 2.5 kilometers $(1.5$ miles) away or by a hydrophone suspended in a heat-flow hole about $1.7 \mathrm{kilometers} \mathrm{(one} \mathrm{mile)} \mathrm{from} \mathrm{Fenton}$ Hil1.

Nevertheless, it was evident that hydraulic fracturing produced acoustic signals that could be detected by sensitive instruments not too far from their sources, and that the events that produced those signals could be located to produce a map of the fractured region. Since the obvious close-in location for an acoustic detector was in a nearby well, a temperature-hardened downhole geophone sonde was developed that contained geophones oriented in three orthogonal directions: one vertical and two horizontal, at right angles to each other. Signals detected by the geophones were transmitted to the surface through a seven-conductor cable, recorded, and analyzed to determine distance and direction from the sonde to the source of the signal. Using this instrument, the hydraulic fractures produced in one of the Phase I wells were mapped successfully by analyzing the signals detected in the other wel1. As is discussed below, both the instrument and the analysis of data from it have since been improved progressively and used to map hydraulic fractures produced in the Phase II wells and in geothermal well-stimulation experiments in California, Nevada, and New Mexico. Instruments based on Los Alamos designs are now available from a spin-off company and at least two other manufacturers and are now widely used to study features of hydraulic fractures. They will be useful not only in well-stimulation operations but also in many other applications - and particularly in early detection of rock failure in mines, tunnels, dams, and underground storage chambers.

\section{Instrument Development.}

Where downhole temperatures above about $100^{\circ} \mathrm{C}\left(200^{\circ} \mathrm{F}\right)$ were encountered during drilling at Fenton Hill, it became evident that most commercial hole-surveying and well-logging instruments were not sufficiently protected against elevated temperatures to be useful in geothermal wells. Many tool failures occurred, and there were often large differences between the results from repeat runs with the same instrument and from similar logs run by different service companies. To satisfy the immediate needs of the Hot Dry Rock Program, it was therefore necessary not only to develop new types of downhole instruments, such as the geophone sonde described above, but a) so to increase the temperature capabilities and reliability of a number of more conventional instruments. Frequently this required development of improved components as well as hardening the tools against high temperatures and pressures. Much of this was done by commercial firms through cooperative arrangements, subcontracts, or purchase orders. However, when appropriate commercial capabilities did not exist or could not provide a necessary tool by the time it was needed, the Hot Dry Rock Instrumentation Group undertook its design, fabrication, and assembly, as well as its testing and use in the field.

Among instruments developed by or for the Hot Dry Rock Program are the following, many of which have been used by field crews from this program in support of other programs and various commercial operations. The designs of all of them for which the Program has had primary responsibility have been made freely available to manufacturers and users of such instruments 
throughout the United States and in several other countries, and design features from them have frequently been recognized in new tools that are now manufactured and used commercially.

1. Steering Tool. The steering tool mentioned above in connection with directional drilling was found during drilling of the Phase II wells to fail frequently as downhole temperatures approached $200^{\circ} \mathrm{C}$. $\left(400^{\circ} \mathrm{F}\right)$. This experience motivated the service company that manufactures and uses it in the field to improve it, particularly with regard to temperature protection. The Hot Dry Rock Program assisted in this by suggesting design changes and testing the improved tool in the Fenton Hill wells and subsequently used it successfully in directionally drilling the Phase II wells at temperatures above $260^{\circ} \mathrm{C}\left(500^{\circ} \mathrm{F}\right)$. It has since been used in high-temperature drilling operations both in the United States and in other countries and, to meet this competition, at least two other service companies have now also developed useful high-temperature steering tools.

2. Borehole Televiewer. The high-temperature borehole acoustic televiewer being developed jointly by the HDR Program and hestfalische Berggewerkschaftskasse is in the final stage of engineering development, and a prototype system should be available for use in geothermal wells in 1986.

3. Geophone Sonde. The high-temperature downhole geophone sonde used for acoustic mapping of hydraulic fractures has evolved continuousiy from the original tool described above, which has required development of several of the special components listed below. Modifications have included an improved mechanism for clamping the sonde against the wall of the hole; increased temperature protection provided by metal dewars, heat sinks, and small heat pipes; substitution of accelerometers for geophones in an instrument designed for use in inclined holes; and, most recently, use of high-temperature electronic components to eliminate the need for temperature protection. These improved tools have been used successfully at temperatures near $315^{\circ} \mathrm{C}\left(600^{\circ} \mathrm{F}\right)$ in the Fenton $\mathrm{Hill}$ wells and, in support of both other programs and commercial operations, in hydrothermal wells in several western states. Acoustic mapping of fractures is now accepted as a widely useful technique, and the downhole tools commercially available for it are based largely on the design of the Los Alamos geophone sonde and incorporate many of its components and design details.

4. Detonator Too1. Accurate measurement of the distance from an acoustic source to a detector requires accurate knowledge of the velocities of the compressive (P) and shear (S) waves as they travel through the intervening rock. Because these velocities vary with the type, structure, temperature, and state of stress of the rock, they must be determined experimentally at each location where measurements are made. These "station calibrations" are usually made by emplacing a geophone in the position that it will occupy in subsequent experiments, then detonating a small explosive charge at a precisely known time at a point as close as possible to that at which acoustic signals are expected to originate -- in 
this case, preferably in the well and at the depth where hydraulic fractures will later be produced.

The explosive usually used for this purpose is a detonator - - a small charge of a sensitive explosive, normally used to initiate detonation of a much larger charge of a less sensitive explosive. The high-temperature detonators initially available to the Program were the product of an earlier transfer of explosives technology from a LOS Al amos project to a commercial manufacturer, who al so produced the downhole firing unit required to explode the detonator. The Hot Dry Rock Program supported development by that manufacturer of a temperature-protected downhole unit that could fire twelve detonators - one at a time, on command from the surface -- mounted on a Los Alamos tool that included a single geophone to detect the exact time at which detonation occurred.

This multiple-detonator tool has been used successfully at high temperatures in the Fenton Hi11 wells, and it has recently been redesigned as a "slimline" (small-diameter) instrument in a modular construction that permits it to be used with other explosive devices. In particular, it has recently been used to fire "string shots" that release about 40 times the energy of a detonator, for use in seismic station calibrations at locations relatively remote from the Fenton Hill wells. "These more energetic charges can also be used for other purposes such as loosening the threads at connections between sections of drill pipe to facilitate their removal when the drill string is stuck in the hole.

To simplify tools of this type and increase their reliability, a new type of high-temperature detonator that does not require a downhole firing unit is now in the final stage of development at Los Alamos National Laboratory.

5. Other Explosive Tools. Special downhole tools using shaped charges have been developed for creating starter cracks at which to initiate hydraulic fracturing; for severing stuck drill pipe cleanly when it cannot otherwise be removed from the hole; and for creating a bell-shaped cavity in the wall of the hole to facilitate sidetracking it. The explosive fracture-initiation tool has been used successfully in the British Hot Dry Rock Program, and the other tools are available for use when they are needed. They are currently being adapted for use with the detonator system described above and a particularly stable high-temperature explosive that is a product of another Los Alamos program.

6. Crosswell Acoustic Transceiver. Both the intensity and the high-frequency content of an acoustic signal are reduced when it passes through a water-filled fracture, and its shear component ( $S$-wave) may be el iminated completely. In "shear-shadowing" experiments in the Phase I wel1s, a geophone was emplaced at a succession of preselected depths in one well, and while it was locked in place, a series of detonators was fired at various depths in the other well. The differences in the received signals between those which had traveled through unfractured rock and those which 
had crossed a water-filled crack gave a clear indication of the height of the fractured zone, and by plotting the ray paths between detonators and geophone, its horizontal position could also be estimated.

To permit continuous collection of data instead of the point-by-point observations made with detonators, an acoustic transceiver was developed for the Hot Dry Rock Program by an instrument manufacturer. It consists of two electronically coupled instruments: a relatively low-frequency, moderate-energy, magnetostrictive, acoustic source and a separate piezoelectric acoustic detector, which can be used one above the other in the same well or as separate units in two wells. When they are used in the same well, the receiver detects the signals reflected from cracks and other discontinuities in the rock around the wellbore, offering a method of mapping fractures and the rock structure around a single well. However, the returning signal is very complex, and additional effort will still be required to learn to interpret it unambiguously. The system has therefore, so far, been used only in the cross-well mode. Since the signal is affected not only by passage through water-filled cracks but al so by rock type and structure, a sophisticated analysis of the received signals can yield a great deal of information about the rock between the two wells -such as the presence of fault zones or changes in rock type -- a technique called "acoustic tomography."

The Hot Dry Rock Instrumentation Group has improved the electronic, acoustic, and mechanical design of the prototype transceiver, and it is now being hardened for use at high temperatures. In the meantime, it has been tested at shallow depths in the Fenton Hill wells and, in support of the U.S. Department of Energy's Multiwell Experiment in Colorado, it has been used successfully to investigate rock structure between natural-gas wells that penetrate low-permeability reservoirs. The "Crosswell Acoustic Transceiver" (or CAT tool) appears very promising for use in oil and gas fields as well as geothermal fields, and between shafts, tunnels, and mine workings as well as drilled holes.

7. Downhole Fluid Sampler. Analysis of unmixed water samples taken at various depths in a geothermal well is important in understanding both hydrothermal reservoirs and the geochemical behavior of hot, dry rock heat-extraction systems. Because of the mechanical and temperature 1 imitations of commercial downhole water samplers, the Hot Dry Rock Program has developed a sampler that operates reliably at temperatures above $260^{\circ} \mathrm{C}$ $\left(500^{\circ} \mathrm{F}\right)$. It has been used successfully in the Fenton Hill wells, in hydrothermal wells in California, Nevada, and New Mexico, and to sample the $285^{\circ} \mathrm{C}\left(550^{\circ} \mathrm{F}\right)$ fluids issuing from seafloor vents under the Pacific Ocean off the west coast of Mexico. It will probably also be used for fluid sampling in the deep, hot wells of the U.S. Continental Scientific Drilling Program.

8. High-Precision Temperature Probes. Downhole temperature probes with high resolution are essential tools in geothermal investigations, not only to measure temperature gradients and bottom-hole temperatures but al so to locate regions in which water enters or leaves the wellbore and to provide information required to analyze the thermal behavior of a 
hydrothermal well or a hot, dry rock heat-extraction loop. Calibrated thermistors are now normally used for such measurements in the Hot Dry Rock Program, but, for special purposes, tools have also been developed using resistance thermometers and thermopiles.

A special tool was developed to determine the undisturbed rock temperature at the bottom of the hole during interruptions in the drilling operation. A hollow phenolic cylinder was attached to the end of the drill pipe and lowered to press against the bottom of the hole, to minimize both conduction of heat up the pipe and convective circulation of fluid where the measurement was to be made. A temperature sensor was then lowered through the drill pipe to make contact with the freshly cut bottom surface of the hole - - which had had minimum exposure to cooling by the circulating drilling fluid. Observation of temperature recovery over a period of a few hours then permitted confident extrapolation to the temperature that existed there before the rock was disturbed by the drilling operation.

9. Hole-Surveying Instruments. The trajectory followed by a hole as it is being drilled is usualty mapped by periodic use of single-shot or multi-shot hole-survey tools. These are lowered to preselected depths, at each of which a camera in the tool photographs a magnetic compass and an inclinometer. When the tool is returned to the surface, the photographic film is developed and read to determine the azimuthal direction and inclination of the hole at the point at which the photograph was taken. This is a relatively quick and inexpensive hole-survey method and is the one that has normally been used in the upper sections of the Fenton Hill wel1s. However, it has the disadvantages that it produces information only at rather widely spaced points along the wellbore, so that it may not detect troublesome "dog legs" (abrupt changes in direction); the compass reading may be influenced by magnetic minerals in the rock around the hole; it cannot be used inside steel casing; and, at high downhole temperatures, the film darkens rapidly to the point at wich the photographic image is obscured.

To increase the temperature capability of instruments of this kind, a successful search was made for seals that would withstand the downhole temperature and pressure and for a type of film that was more resistant to darkening from exposure to high temperature. However, the resulting improvement was not large, and the other disadvantages of the tool remained. Accordingly, interest developed in the use of gyroscopic hole-survey instruments instead. These produce a continuous record of hole direction and inclination and are not affected by either magnetic materials or shielding by steel casing around them.

When two service companies were called in to run gyroscopic surveys in one of the Phase I wells, it was found that neither of their tools was adequately protected against downhole temperatures, both gave somewhat inconsistent results from one run to the next, and borehole trajectories mapped by the two companies departed more and more widely from each other as depth increased. The HDR Program therefore sponsored development by both companies of more reliable downhole instruments with improved temperature protection. The improved tools have since been used successfully in the Phase II wells at Fenton Hill and in other hot wells around the world. 
One means of verifying the accuracy of well surveys that has been used by the HDR Program is acoustic ranging, in which distance and direction from one well to the other are measured at various depths by the use of detonators in one hole and a geophone in the other. Another method that has been used where the two wells approach each other quite closely is electromagnetic ranging, in which a magnetometer placed in one well is used to observe the disturbance in the earth's magnetic field that occurs when a powerful magnet is lowered in the other well.

The commercial fluxgate magnetometer used for this purpose has also been combined with an inclinometer in a hole-survey tool that is now used routinely for well surveys at the Nevada Test Site. It has not so far been hardened against high temperature; otherwise, it could also be used for hole surveying and as a steering tool for directional drilling in hot wells.

10. Fluid Injectors. Two types of tools have been developed to inject tracers or other chemicals into the well at preselected depths. One, used for such things as fluorescent dyes, releases the chemical when a fusible-alloy plug melts, the alloy selected being one that melts at the known temperature corresponding to a particular depth. The other is primarily for use with radioactive tracers, which are contained in glass ampoules within radiation shielding near the lower end of the tool. When the tool has been lowered to the desired depth, an electric motor -controlled from the surface -- advances a plunger that crushes the ampoule and releases its contents, which are then flushed out into the well.

11. Independent-Arm Caliper Tool. Precise measurements of the inside dimensions of a wellbore are used to inspect the casing for damage, estimate the amount of cement that will be required to cement-in casing, search for large open fractures, identify smooth sections of the hole where packers can be expected to seal against the wall, and for other purposes. These measurements are made with borehole calipers, which are raised or lowered in the hole while spring-loaded, radially-arranged arms extending from the tool follow the contours of the hole wall. In most commercial caliper tools, the electrical signal sent to the surface indicates only the average distance to which the arms are extended or else the position of that one arm which is extended farthest.

To derive more information from a tool suitable for use in a geothermal well, the HDR Program has developed a temperature-hardened caliper tool that has three independent arms located $120^{\circ}$ apart around the circumference of the body of the tool, which is held at the center of the hole by bow-spring centralizers. The positions of all three arms are signaled to the surface continuously, permitting, for example, distinctions to be made among a circular or spiral groove worn by a drill bit, an inclined open fracture, or a small cavity in the borehole wall -- all of which might look the same in the record produced from a single caliper arm and might not be seen at all if the positions of several arms were averaged. This three-independent-arm caliper tool has been used very successfully in the Fenton Hill wells for a variety of purposes, and the design is readily adaptable to four or more independent measuring arms. 
12. Spinner To01. A spinner tool measures fluid velocity by measuring the rate at which a bladed rotor is turned by the fluid moving through it. In the HDR Program, a commercial spinner tool has been modified to increase its sensitivity and adapt it to use at high temperatures. In conjunction with measurements of borehole dimensions (made with the caliper tool described above), it is used to measure volumetric flow rates up or down the hole at various depths. This permits determination of the rate at which water leaves or enters the well at each fracture. Repeated measurements with the spinner and temperature tools can then be used to follow the history of flow rate and heat extraction in each fractured region, which is important in understanding the mechanical and thermal behavior of the heat-extraction loop.

Spinner tools are also useful in hydrothermal and many other types of wells. For example, an HDR field crew and logging truck participated in a geothermal well-stimulation experiment in Oregon, in which it was impossible to raise the downhole pressure sufficiently to produce a hydraulic fracture. Spinner and temperature logs showed that all water pumped into the well was leaving it freely through casing perforations at a level far above that at which it was intended to produce a fracture. The existence of those perforations was unknown before the fracturing attempt was made.

A number of other high-temperature downhole tools have also been developed by the HDR Program, including a gamma-survey tool, collar locators, and self-potential and induced-potential probes.

As has been indicated in the discussions above, several of these tools have been used by HDR field crews (usually with one or both of the specially equipped HDR logging vans) in support of other programs and industrial operations away from Fenton $\mathrm{Hill}$, when conditions were such that capabilities were required beyond those available from commercial sources. Detailed information about all of them has been provided freely to anyone that was interested in them.

\section{E. Component Development}

Many of the equipment and instrument developments described above have al so required development of new or improved components, and many of these have found even broader applications outside the HDR Program than have the tools themselves.

1. Seals. Elastomeric seals to prevent fluid intrusion into bearings, electronic devices, acoustic transducers, and other sensitive locations, or to prevent flow up or down the wellbore, are a constant problem at the temperatures and pressures encountered in a geothermal well. The need for improved elastomers for use in mud motors and float valves, discussed earlier, is one example of the problem.

In 1978-80, the HDR Program sponsored fabrication by a commercial organization of a new high-temperature elastomer called "EPDM" into 0-rings and other types of seals -- which have been used successfully in many of 
the Los Alamos tools described above. Under other sponsors, the EPDM technology has since been extended and transferred to several manufacturing concerns. A wide variety of seals and other products made from this very useful high-temperature elastomer is now commercially available.

2. Instrument Cables. Information from downhole instruments and electrical power to control or operate them is ordinarily transmitted through an armored instrument cable on which the instrument itself is suspended. The cable must resist penetration by fluids in the well, which would cause short-circuiting among the electrical conductors or from them to the metal armor. It must also withstand abrasion against the borehole wall and repeated bending over sheaves and around a cable drum at the surface. Such cables are very expensive, and in the past they have not been designed to survive in the high-temperature geothermal environment. There have been many cable failures at Fenton $\mathrm{Hill}$ and el sewhere, both of cables acquired by the HDR Program and of those provided by service companies.

To alleviate this problem, a development and testing program was conducted jointly by the HDR Program, Sandia National Laboratories, and two cable manufacturers. Seven-conductor, TFE-Tefion-insulated, armored instrument cables were developed, which have been used successfully in the deepest Fenton $\mathrm{Hill}$ well at temperatures up to $315^{\circ} \mathrm{C}\left(600^{\circ} \mathrm{F}\right)$. These are now commercial products.

3. Cable Head. This is the mechanical and electrical connection between the instrument cable and the instrument suspended from it, and it must protect them both from fluid intrusion and mechanical damage. Commercially available cable heads were not designed for use in geothermal wells, and they failed quickly in service at Fenton Hill -- often with serious damage to the cable, the instrument, or both. The HDR Program therefore developed a cable head that has been used successfully at temperatures up to $315^{\circ} \mathrm{C}\left(600^{\circ} \mathrm{F}\right)$. This design has been adopted by several service companies that $10 \mathrm{~g}$ geothermal and hot gas wells, and has also been used in the British Hot Dry Rock Program.

4. Thermal Protection. In a cooperative program with an industrial concern, a family of small-diameter metal dewars (vacuum-jacketed "thermos bottles") was developed to protect temperature-sensitive electronic components within the downhole instrument package. These dewars are now available commercially, and two other companies now al so manufacture similar products.

To avoid overheating within the dewars from heat generated by the electronic components, heat-absorbing "heat-sink" materials have been included in the interior of the dewar in several Los Al amos instruments. When this did not prove as effective as was expected in extending the safe residence time of a downhole tool, thermal modeling showed that the deficiency was in the rate of heat transfer from source to sink. To correct this, heat pipes (another Los Alamos development) were added to the design. 
While this type of temperature protection works very well, recent developments in high-temperature electronics have now made it possible to construct some downhole tools without any temperature protection. This greatly facilitates design of small-diameter "slimline" tools such as the detonator tool and geophone sonde mentioned above.

5. Electrical Connectors. The connectors that conduct electrical current between the cable head and the instrument package have al so been a frequent source of problems. Under contract to the HDR Program, a commercial manufacturer has recently developed a new type of connector based on use of a machinable ceramic insert in the ends of the cable head and instrument sonde. The inserts accept crimped pins that are readily inserted and removed, which allows the connector to be reused repeatedly. These connectors have been tested in the 1 aboratory at up to $350^{\circ} \mathrm{C}\left(660^{\circ} \mathrm{F}\right)$ with no evidence of degradation, and they are now being incorporated in new instrument designs.

6. Motors. Very small high-temperature electric motors are required in several of the tools described above, for example to extend the arms of the caliper and to advance the piston that crushes a glass ampoule in one type of fluid injector. Small direct-current motors that can withstand geothermal temperatures were developed for the HDR Program in 1976-78 by an industrial manufacturer, and they have operated reliably in the Fenton Hill wells. They are now a commercial product, and generally similar motors are now marketed by at least two other motor manufacturers.

7. Geophones. High-temperature geophones suitable for use in the downhole acoustic detectors designed by the HDR Instrumentation Group have been developed and improved over a period of years by their manufacturer, with direct support and participation by HDR Program personnel. Their most recent improvement is a geophone suspension that is insensitive to tilt, making it unnecessary to substitute accelerometers for geophones when an instrument is to be used in an inclined hole.

8. Special facilities. The design, fabrication, testing, evaluation, calibration, field operation, and repair of unique, highly specialized components, instruments, and downhole equipment, have required very broad developmental capabilities at Los Alamos National Laboratory.

Much of the 1aboratory and shop equipment used for fabrication and initial testing of components and subassemblies is conventional, al though unusual facilities are required, for example, to evaluate stressed instrument cables at high temperatures and pressures or the ability of a shaped explosive charge to sever drill pipe cleanly.

Beyond this, an Instrument Sonde Test Facility (ISTF) has been constructed at the Laboratory to test fully assembled downhole instrument packages and other large tools and equipment under realistic conditions of temperature and pressure. Essentially, this is a highly instrumented underground autoclave that can accommodate items up to 15 centimeters (6 
inches) in diameter and 6 meters (20 feet) long and expose them to temperatures up to $275^{\circ} \mathrm{C}\left(525^{\circ} \mathrm{F}\right)$ at pressures up to 41 million Pascals (6000 pounds per square inch). It is used to test experimental and prototype units of many types and al so to check the seals and electrical and mechanical operations of assembled instrument packages before they are taken to the field.

The wells, equipment, instrumentation, and support facilities at Fenton Hill represent a unique capability for field-testing downhole instruments and other types of downhole equipment.

Two highly instrumented logging trucks equipped with high-temperature instrument cable and sophisticated data-acquisition and recording systems are used routinely at Fenton $\mathrm{Hill}$ and are available for use almost anywhere el se.

While these facilities were developed and are used primarily to satisfy the direct needs of the Hot Dry. Rock Program, they are available on a cooperative basis for testing and evaluation of commercial products or to support other programs or industrial operations when commercial capabilities for such work do not exist or cannot be obtained. For example, HDR laboratory facilities have been used to investigate the reactions that occur during hardening of commercial cement formulations under a variety of conditions, to test high-temperature polymers and elastomers, and to evaluate many different electronic components. The ISTF has been used to test commercial seals, the wiper plugs used in cementing operations, pressure housings, and a downhole detonator-firing package. Cements, televiewers, steering tools, and drill bits have been tested in the Fenton Hill wells. And the HDR logging trucks, special instruments, and field crews have participated in geothermal-well-stimulation experiments in California, Oregon, Nevada, and New Mexico, in cross-well acoustic-mapping studies in a natural-gas field in Colorado, in vertical seismic-profiling investigations in California, and in ground-noise studies in Nevada.

These special capabilities and facilities are essential to the daily operations and continued progress of the HDR Program, but they are also a unique national resource that is available to other projects and to the private sector when their particular needs cannot be met el sewhere.

F. Geochemistry

The general usefulness of geochemistry in geothermal exploration and site characterization and in monitoring hydrothermal wells and HDR heat-extraction systems has been mentioned. These and other requirements of the Hot Dry Rock Program have made it necessary to undertake a variety of geochemical investigations and to develop special capabilities, techniques and facilities for them. Many of these are also directly useful outside of the HDR Program, and have produced information that is broadly useful to the geothermal and other industries and to the earth sciences in general. 
1. Rock-Water Interactions. Water circulating through the fractures of an HDR heat-extraction loop can be expected to alter some of the minerals with which it comes in contact, which could result in plugging of the fractures, and to dissolve other minerals, which could lead to corrosion, scaling, or plugging in the surface facilities, the injection well, or the fractures around that well. To evaluate these possibilities, rock-water interactions as functions of temperature, pressure, and mineral content have been investigated in the 1 aboratory in both static and flowing systems, and during flow-testing of the Phase I system at Fenton Hill.

At Fenton Hill, a sophisticated analytical facility monitors the chemistry of the injected, recirculated, and stored fluids, and provides an analytical service to many other activities within and outside the HDR Program. A rapid analytical method for determining the radon concentration in gases vented from the Phase II wells has recently been developed there, together with the special apparatus required for the analysis.

The information on rock-water interactions that is collected and published applies not only to HDR systems but also to hydrothermal systems, to the effects of groundwater circulation in general, and to the formation of mineral deposits.

2. Natural Waters. The dissolved-mineral content of surface and groundwaters depends upon both the type and the temperature of the rock with which the water has been in contact, and several types of "chemical geothermometers" have been developed (notably by the U.S. Geological Survey) which permit the highest temperature previously reached by the water to be estimated from its chemical composition -- even after it has cooled or mixed with other water. This type of geochemistry is therefore a primary tool in prospecting for geothermal areas, and particularly where hot springs or wells are found, in estimating temperatures at the depths reached by the groundwater circulation. It is also very useful in investigating the hydrology in and around geothermal areas by determining the degree to which the compositions of surface and groundwaters are affected by mixing with the thermal water.

In the HDR Program, chemical monitoring of spring, well, and surface waters was initiated primarily to provide assurance that the Fenton Hill operations had no effect on water supplies away from the site. However, in a separate program, this study has been extended to an investigation of a high-temperature hydrothermal system in the nearby Valles Caldera and to the drainage of thermal water from it. This in turn has contributed to a separate study of the probable effect of a commercial hydrothermal development within the caldera on water supply and downstream water rights in the drainage area around it.

Again in separate programs, these capabilities have been used to investigate many other hydrothermal systems, ranging from a smal1, low-temperature system at $0 j 0$ Caliente in northern New Mexico to a very promising high-temperature system on the island of St. Lucia in the Caribbean. 
3. Inert Tracers. One of the very few methods available to investigate the internal flow characteristics of a fractured reservoir is the use of chemical tracers. In general, these are substances that are soluble in the fluid flowing through the reservoir, stable at reservoir temperatures, not trapped within the reservoir by chemical reactions or physical interactions (such as adsorption on rock surfaces), and quantitatively measurable at very low concentrations in the fluid leaving the reservoir. The HDR Program has pioneered in the use of chemical tracers to investigate flow in fractured reservoirs.

In a tracer experiment in an HDR reservoir, the usual procedure is to introduce the tracer as a pulse into the water entering the fracture system and then to monitor its concentration in the fluid leaving the system -- as a function of time if flow rate is constant, or of fluid volume if it is not. If the tracer appears quickly in the production well, it is an indication of short-circuiting (i.e., of undesirably direct flow paths through the reservoir). The volume of fluid that has passed through the system before the peak concentration of tracer is reached in the produced fluid is one measure of the volume of the fracture system. The height and shape of the concentration peak are determined by the degree of mixing within the reservoir of the fluid containing the tracer with that which preceded and followed it. They may also indicate existence of more than one major flow path through the reservoir and, if there is a long "tail" on the concentration vs volume curve (called a "Residence-Time Distribution Curve") significant flow through paths outside of the main fractures.

Laboratory experiments early in the Program showed that sodium fluorescein dye met the major requirements outlined above, and it was used successfully in many tracer experiments in the Phase I system. However, subsequent experiments showed that a radioactive bromine isotope, $\mathrm{Br} 82$, was an even better tracer. It has a conveniently short half-life (about 35 hours), so that it disappears quickly from the system after a test is completed. It emits a strong (about $1 \mathrm{MeV}$ ) gamma ray, so that it can be detected even through steel well casing. Its concentration can be measured accurately at concentrations far below the detection limit of a dye, and the measurement can be made downhole with a gamma logging tool so that flow distribution among individual fractures can be determined quickly and accurately.

The tools, techniques, and analyses developed in the HDR Program will make tracer studies valuable wherever there is flow of a liquid between two or more wells.

4. Chemically Reactive Tracers. Prediction of the useful lifetime of an HDR heat-extraction loop is an extremely important and very difficult problem. The obvious method of making such a prediction is to monitor the temperature of fluid leaving the fracture system, over a sufficient period so that the rate of temperature decrease can be extrapolated to the time at which the fluid temperature will be too low to be useful. However, during nine months of heat extraction from the relatively small Phase I system, the temperature decrease was only $9^{\circ} \mathrm{C}\left(16^{\circ} \mathrm{F}\right)$ and the rate of decrease was too low to permit confident extrapolation. In a much larger commercial system, no significant decrease would be expected for several years. It 
therefore is important that some other basis be provided for estimating system lifetime, after a much shorter period of testing.

The tracer tests described above give a rough measure of the volume of the fracture system, and pressure-flow tests and a recently developed chemical method, described below, can provide an estimate of the average width (the "aperture") of the fracture openings. From those, the total surface area of the fracture system can be calculated. Then, from the rate of fluid circulation and the thermal conductivity of the rock, the rate of temperature drawdown of the thermal reservoir can be estimated. However, all of this involves many uncertainties, particulariy with regard to the distribution of flow paths through the reservoir and the extent of thermal interactions among them. At least until enough information has been collected to show that there is a consistent average behavior of fractured reservoirs, some type of direct measurement of thermal drawdown will be needed.

A possible method of doing this is the use of chemically reactive tracers whose reaction rates are sensitive to temperature in the range of temperatures expected in a cooling hot, dry rock reservoir. These tracers could be injected with the fluid entering the fracture system and the extent to which reaction had occurred measured in the fluid leaving it. A series of such tests over a period of time would show a decrease in the extent of the reaction long before there was detectable cooling of the fluid leaving the fracture system. Particularly if several tracers with different reaction rates were used, these results could be used to model the progress of cooling away from the injection well. Alternatively, the reactive tracer could be pumped down the injection well, held in the fracture system long enough to permit significant reaction to occur, then flowed back to the surface through the same well. The first fluid to return would be the last that was pumped in and would show the least reaction - - because it had encountered only the coolest rock, adjacent to the injection we11. Fluid returning later would show more reaction, permitting a curve to be drawn of temperature vs distance into the reservoir. With either technique, repeated measurement would indicate progress of a cooling wave through the reservoir, and permit extrapolation to the time at which it would reach the production well.

A wide variety of reactive chemicals have been investigated in the laboratory for this use, and the hydrolysis reaction of ethyl acetate appears to be well suited for use over the temperature range $80^{\circ}$ to $200^{\circ} \mathrm{C}$ $\left(175^{\circ}\right.$ to $\left.400^{\circ} \mathrm{F}\right)$. Less reactive esters will be required for use at higher temperatures.

Drawdown studies by this general method will be attempted in the Phase II system at Fenton Hill. There are obvious uncertainties in the method, but it should at least be a valuable supplement to the calculational method described above.

5. Estimation of Fracture Aperture. Another method of estimating fracture aperture is made posible by the presence of radon in the fiuid circulated through the fracture system. 
Radon is a decay product of the small amount of radium present in the reservoir rock, and is normally present in geothermal fluids. Because radon is also radioactive, the amount present can be measured quantitatively even at very low concentrations. The radon atom ejected by the radium atom travels only an extremely limited distance through the rock, so that the radon reaching the circulating fluid comes entirely from a very thin layer of reservoir rock along the fracture surface with which the fluid is in contact. The total amount of radon accumulated by the fluid in one passage through the fracture system can therefore be reduced to a measure of the surface area of rock along the circulation path -although the calculation is complicated by decay of the radon as it is transported by the fluid. Further, the concentration of radon in the fluid leaving the fracture system is a measure of the volume of fluid that was in contact with each unit area of rock surface, which can be reduced to an average thickness of the fluid layer -- and thus to the average width of the fracture openings.

Relatively long residence times of fluid in the fracture system are required for the fluid to accumulate enough radon for a sensitive measurement of fracture aperture, although this is being reduced by development of the analytical apparatus mentioned above. Further improvement of the method will occur as experiments proceed in the fractured reservoir of the Phase II system.

\section{G. Reservoir Engineering.}

In the HDR Program, reservoir engineering is considered to include a wide variety of activities, a number of which have al ready been described. These range from laboratory-scale rock mechanics studies through drilling, hydraulic fracturing, determination of reservoir characteristics, and flow testing, to analytical and computer modeling of all aspects of the laboratory and field operations. Among reservoir-engineering activities of interest beyond the HDR Program are the following.

1. Acoustic Fracture Mapping. As has been discussed, the development of the methods and instruments for acoustic mapping of fractures by the use of downhole instruments is one of the most important contributions so far made by the Hot Dry Rock Program. This technology is now widely accepted and used but, al though it is already quite highly developed, further improvements are still being made.

In use, the downhole geophone sonde is clamped firmly against the wall of the hole so that it will move with the rock around it as the elastic waves that compose the acoustic signal move past the wellbore. This movement can, however, induce vibrations in the sonde which are superimposed on the actual movement of the sonde as a whole and may seriously distort the signal that is transmitted to the surface. Since the distance from signal source to geophone is determined from the difference between the arrival times of the compressive (P) and shear (S) waves -which travel through the rock at different velocities -- the distance measurement is not affected by such vibrations. However, the direction from geophone to signal source is measured by a hodogram technique, which 
depends upon precise measurement of the slopes of the early parts of the displacement vs time records of the signals transmitted by the geophones. These can be strongly affected by vibrations of the sonde, introducing a large uncertainty in the directional measurement. Numerical analysis of vibrational modes and physical testing of assembled geophone sondes have been undertaken that should permit an improved design of the sonde to minimize this uncertainty.

In the meantime, the directional uncertainty has already been reduced by the use of a "partial two-tool hodogram technique," in which analysis of the signals from the triaxial geophone package is supplemented by a distance measurement provided by another geophone emplaced in a different welloore. This technique is now being improved further by also incorporating a directional measurement from the second geophone package into the analysis.

2. Seismic Signal Analysis. The acoustic signal contains information not only about the location of the source but al so concerning the nature of the event that produced the signa1. Good progress has been made in investigating the source mechanisms by a sophisticated analysis of the forms of the acoustic waves. For example, spectral analysis of the signals from 50 well-located events that occurred during a massive hydraulic-fracturing experiment in the deeper of the Phase II wells indicated that they were similar to exceedingly small natural earthquakes. They involved shearing displacements of 10 to 100 micrometers $10.000,4$ to 0.004 inch) over areas of 10 to 300 square meters (100 to 3000 square feet) - resulting in a local decrease in stress of about 100 thousand to 1 million Pascals ( 15 to 150 pounds per square inch). The cumulative seismic moment (related to the amount of energy released) was only about $0.1 \%$ of that estimated from present theory, suggesting that most of the energy involved was dissipated by some mechanism other than shearing displacement - probably in the opening of tensile fractures, which may occur with very little emission of acoustic energy. A search of the geophone records is now being made for the low-frequency, low-amplitude signals representative of tensile fractures, which tend to be masked by the more energetic shear signals. A number have been found, and the search is continuing in the hope that the tensile fractures -- which probably are the main paths for fluid flow - can be mapped directly instead of by association with the source locations of shear signals.

Information of this type is basic to understanding the mechanism of hydraulic fracturing and the characteristics of the fracture system produced, and it cannot be obtained from the testing of small samples in the laboratory.

3. Evaluation of In Situ Stress Field. The conventional method of measuring in situ earth stress at depth is by hydraul ic fracturing, which is difficult in deep, large-diameter holes in hot rock. However, with development of improved high-temperature open-hole packers, successful measurements of this type have been made repeatedly in the Fenton Hill wells. Unfortunately, the only information derived directly from such a measurement is the magnitude of the minimum compressive stress (the "least principal earth stress") that exists at the depth at which the fracture was 
produced. If the fracture is mapped acoustically, the direction in which the stress is least can also be estimated.

During hydraulic-fracturing experiments in the deeper (Phase II) wells at Fenton Hill, the energy release from individual fracturing events has been sufficient so that well-resolved microseismic signals could be recorded by sensitive geophones at the earth's surface. Data from an array of surface geophones emplaced around the site were therefore available for two principal uses. First, knowing the velocities of acoustic waves traveling through the intervening rock, their arrival times at the various geophone stations were used to locate the sources of the acoustic signals -- which was one of the methods used to map the hydraulic fractures. Second, knowing the source location and the direction of particle motion indicated by the slopes of the displacement vs time records of the first arrivals of the acoustic signal at the geophone locations, a mathematical analysis called a "fault-plane solution" was used to determine the orientation of the fracture and the direction in which shearing displacement had occurred along it. This in turn indicated the orientations of the axes of the minimum, maximum, and intermediate compressive stresses -- although significant uncertainties were introduced by the fact that at least some of those displacements were probably along preexisting fractures that were near but not exactly at the orientation of the plane on which the shear stress was greatest.

Again, however, this information represents the stress field only at the location at which the fracturing event occurred. To investigate changes in the stress field with depth, anelastic-strain-recovery measurements have been made on oriented cores cut at various depths during drilling operations. These are very precise, repeated measurements of the dimensions of a freshly cut core, made to observe the time-dependent relaxation of the stresses that remain in the rock after it is brought to the surface. This has been supplemented in the laboratory by bonding strain gages to the core and overcoring (i.e., removing a smaller core surrounding the strain gage) to release residual stresses in this smaller core. In situ stress directions and magnitudes have al so been estimated from determinations of microcrack intensity and orientation by the differential-strain-analysis technique, in which an array of strain gages is used to measure dimensional changes as a rock specimen is subjected to increasing hydrostatic pressure.

In combination with the other experimental methods described above, these observations have produced important new information on in situ stresses as functions of depth in a major geothermal area associated with geologically recent volcanism.

4. Flow in Fractured Reservoirs. Analysis of fluid flow in and heat extraction from a fracture system such as that produced in the massive hydraulic-fracturing experiment mentioned above must take into account both the shearing and tensile displacements that have occurred throughout a very large, three-dimensional volume of rock, and also the elastic deflections produced by fluid pressure. (The importance of the latter is apparent, for example, in a large reversible reduction in flow-impedance through the Phase I fracture system when downhole fluid pressure was increased.) A complex computer program called FRIP has been developed to do this. 
FRIP is an acronym for "Fluid-Rock Interaction Program." It was originated by personnel of the British Hot Dry Rock Program and a rock-mechanics consultant to them. Its development is continuing in a collaborative effort between the British and U.S. programs with the advantage that the advanced computer facilities at Los Al amos National Laboratory permit analysis of the behavior of 1 arger and more realistic model s. Important insights have already been gained into the importance of the relative orientations of earth stresses and existing fractures, and the extension of fractures and flow paths into a connected three-dimensional network. This type of background information is essential to the understanding not only of fluid flow and heat extraction but also of the significance of the acoustic signals generated by hydraulic-fracturing operations - which can be useful in predicting the characteristics of the fractured reservoir before a second well is drilled.

5. Spallation Drilling. To provide a basis both for improving spallation-drilling equipment and procedures and for predicting their performance in the field, theoretical and laboratory studies of the drilling operation have been conducted at Los Alamos National Laboratory. For the first time, detailed fluid-dynamics and heat-transfer models have been developed that simulate the supersonic flow from the flame-jet burner and its interactions with the boundary layers next to the rock and with the rock itself. Coupled with a rock-mechanics model based on Weibull failure statistics, this permits calculation of spall size and drilling rate. Results are verified in the laboratory using welding torches and high-powered lasers as heat sources to spall samples of typical rock types under a variety of conditions.

This fundamental investigation is continuing. It has al ready produced much information that is directly useful in increasing the efficiency and versatility of spallation-drilling equipment.

\section{CONCLUSION}

The fact that the temperature of crustal rock increases quite rapidly with depth below the earth's surface has been known for hundreds of years. However, except where some of the natural heat has been brought to or nearly to the surface in the convenient form of hot water or steam, no practical method for extracting this heat and bringing it to the surface was proposed until the 1 ate $1950^{\prime} \mathrm{s}$. The initial proposal, which was studied intensively and broadened considerably in the 1960's, was to use nuclear explosives to create a large volume of broken rock into which water would be injected and from which steam would be recovered. In addition to a widespread emotional reaction against any use of nuclear explosives, the requirement for continuous, 1 ong-term, environmental monitoring of the site at which they had been used would add so much to the cost of such a system that its economics become very unattractive. The second practical proposal, which is the basis of the Hot Dry Rock Program discussed here, was to use hydraulic fracturing instead of nuclear explosives to fracture the rock.

The most important technology transferred from the Hot Dry Rock Program has been the information that there now exists a safe, practical, 
environmentally benign method of extracting useful heat from the earth's crust, and that the technology for doing so on a large scale at reasonable cost is in the final stages of engineering development.

In the meantime, however, as has been outlined above, the special requirements of the Hot Dry Rock Program have already led to a wide variety of broadly useful technological developments that have been and are being transferred to other programs and to the private sector.

\section{ACKNOWLEDGMENTS}

Under an International Energy Agency "Implementing Agreement for a Programme of Research, Development and Demonstration of Hot Dry Rock Technology," the Fenton Hill Hot Dry Rock Geothermal Project has been sponsored jointly by the United States Department of Energy, Kernforschungsanlage Julich GmbH representing the Government of the Federal Republic of Germany, and the New Energy Development Organization representing the Government of Japan. Project activities are centered at Los Alamos National Laboratory, Los Alamos, New Mexico, U.S.A., whose facilities include the Fenton $\mathrm{Hill}$ experimental site.

The work here reported is the product of all participants in the Hot Dry Rock Geothermal Energy Development Program, of which the Fenton Hill Project is the major component. These include project personnel from West Germany, Japan, and the United States, together with representatives of many industrial organizations, colleges and universities, and governmental agencies in the United States and other countries. Their contributions to the Hot Dry Rock Program and to this report are gratefully acknowledged. 